\title{
PERSPECTIVAS DE GOBERNANZA EN INTERNET
}

\author{
Por Carolina Aguerre
}

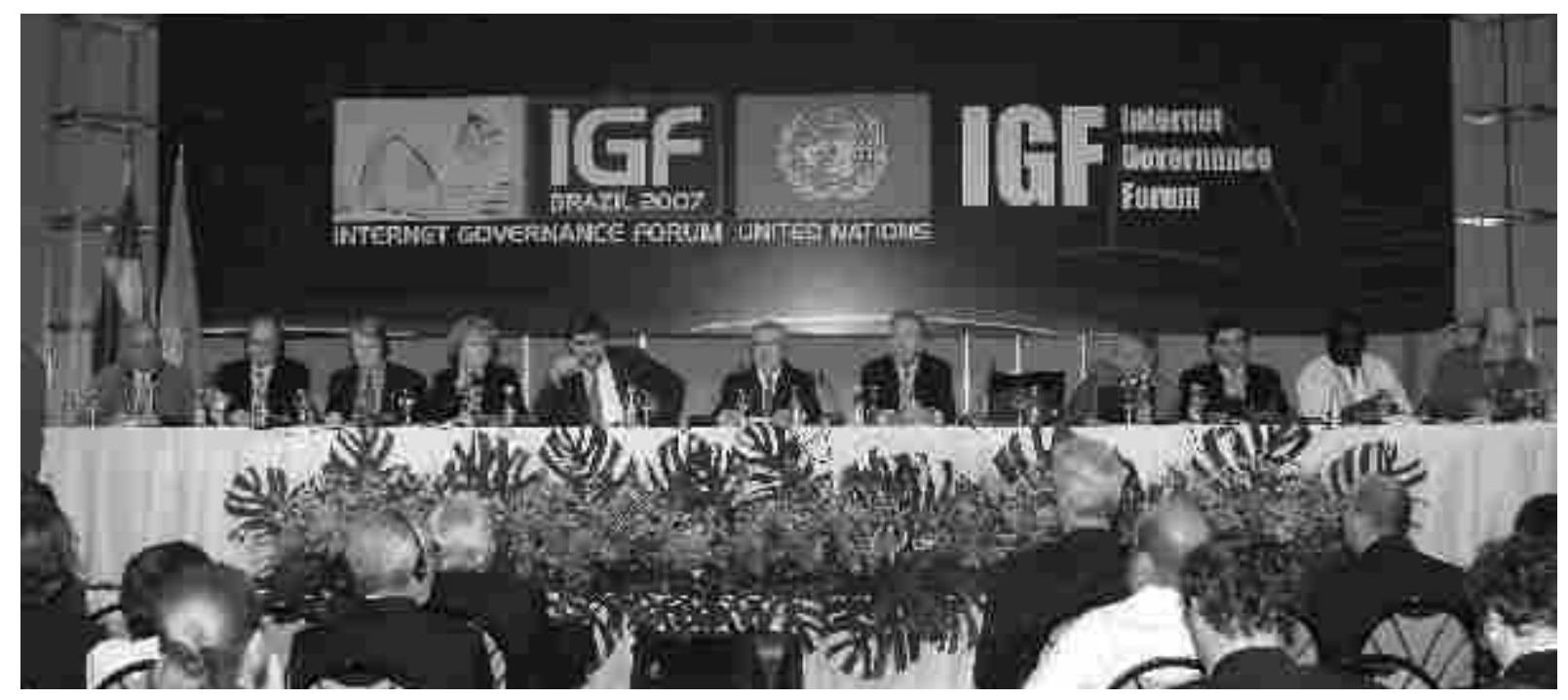

$1::$

El foro de gobernanza de Internet (IGF) es un foro multisectorial que busca establecer políticas públicas que garanticen la robustez, sustentabilidad, seguridad y desarrollo de Internet; facilitar la discusión entre las distintas partes y asesorarlas; identificar temas emergentes; y promover un buen uso de Internet. Las Naciones Unidas respaldan este proyecto que tiene garantizada una continuidad de cinco años.

Para comprender al mosaico hay que recorrerlo, y el punto de llegada y de partida nunca es el mismo. En su recorrido se

conforman figuras que adquieren una forma particular y relevante para cada persona,

por oposición al aprendizaje lineal donde lo fundamental es

transitar un solo camino.

El IGF 2007 tuvo lugar en Río de Janeiro del 12 al 15 noviembre. Congregó a 1400 participantes de diversos países, gobiernos, empresas,

organismos internacionales,
Este artículo se propone hacer un recorrido por el Internet Governance Forum (IGF), ${ }^{1}$ actualmente el ámbito más importante de debate mundial sobre Internet. La idea es recorrerlo desde la figura del mosaico ${ }^{2}$ que permite abordar un tema de esta magnitud desde múltiples perspectivas, ya que la delimitación de una forma precisa para evaluar el impacto de un evento de estas características no sólo puede resultar soberbio, sino también muy parcial.

El debate sobre la gobernanza tiene lugar porque Internet es de todos pero no le pertenece a nadie, no hay sólo una empresa o laboratorio universitario centrado en su desarrollo, ni los usos que se hacen sobre esta plataforma de redes son los mismos, y la experiencia que provoca impacta distinto según la edad, contexto social, región, género o profesión. Además, trasciende las fronteras de interés y soberanía de una sola institución o Estado. Entonces, al hablar de gobernanza de Internet se intenta dar cuenta de las formas que tiene para los distintos actores involucrados, manteniendo un equilibrio entre las perspectivas sin que una voz predomine sobre otras. El IGF es un espacio de debate y de propuestas para una mejor Internet, que si bien no es un ámbito facultado para la toma de decisiones, es el lugar donde surgen algunas de las principales recomendaciones que le dan forma a las políticas de Internet en el sistema de Naciones Unidas.

En el IGF de 2007 en Río de J aneiro, ${ }^{3}$ Ios grandes temas de discusión estuvieron centrados en el acceso, ${ }^{4}$ la diversidad, ${ }^{5}$ la apertura ${ }^{6}$ y la seguridad ${ }^{7}$ de Internet. Se incluyó una sesión principal sobre recursos críticos de Internet, un tema considerado clave en la pasada reunión de A tenas. Uno de los puntos centrales sobre los recursos críticos es el pasaje de Internet basada en el protocolo IPv4 al IPv6, un tema que afecta el funcionamiento dela red, ya que sobre la base del IPv4 se agotarán las direcciones de IP en un plazo de dos a tres años. Para ello Vint Cerf, uno de los creadores de Internet, recomendó que los usuarios exijan a sus proveedores direcciones en el IPv6, ya que muchos proveedores de acceso a Internet (ISP) aún lo ven como un problema lejano. Cerf, que se paseó por todas las sesiones plenarias y asistió a todos los talleres 
posibles, fue un activo participantey orador. Para Cerf, Internet fue diseñada sin gatekeepers sobre los nuevos contenidos o servicios que se puedan crear sobre ella. La neutralidad de la red es para él, como para muchos, un principio central de la arquitectura de Internet. Este es uno de los puntos más álgidos sobre las discusiones en Internet. En el IGF en Río se manifestó desde el comienzo con mucha fuerza, y logró definir claramente los bandos de amigos y opositores de este principio.

La neutralidad de la red o Net Neutrality (NN) es un principio que se aplica para la no discriminación de las aplicaciones que se realizan sobre la red, y para la no discriminación de contenidos e información. Los detractores de este principio se encuentran en primer lugar en las empresas, ya que estas precisan generar barreras de entrada sobre los servicios que ofrecen para que sean rentables como negocios. El controvertido acuerdo de Apple con AT\&T en 2007, por el cual el iPhone sólo debía funcionar sobre la red de AT\&T es un claro ejemplo. Otro grupo muy diferente de detractores de la NN son los defensores de derechos del niño, o los que luchan contra las formas de discriminación. En este sentido la legislación de varios países, como Francia que prohíbe sitios vinculados a los grupos neonazis, adhiere al principio de discriminar en base a los contenidos que se transmiten sobre la red. Pornografía infantil, abusos físicos, discriminación y exaltación de la violencia y el terrorismo, son todos temas que en primera instancia tienen muchos simpatizantes. Pero, como dijo el profesor de Syracuse University y dela Universidad de Delft en Holanda, Milton Muller -uno de los defensores más acérrimos del principio de neutralidad sobre la red-esto hoy puede llevar a prohibir determinados contenidos pero en el futuro va a ser cada vez más fácil levantar barreras sobre las aplicaciones (un beneficio para las empresas) y otros contenidos podrían pasar a censurarse con más facilidad. Para Muller, el principio de neutralidad sobre la red debe ser el principio rector para la gobernanza de Internet.

Diversas universidades, ONG y organismos internacionales manifestaron su creciente preocupación por la distancia cada vez mayor en materia de Internet entre países desarrollados y los que están en vías de desarrollo. La problemática, que para muchos se vislumbra desde los problemas de acceso o de capital social para aprovechar las Tecnologías de la Información y Comunicación (TIC), tiene un lado mucho menos conocido vinculado a los derechos de propiedad intelectual y los estándares técnicos. Laura Nardis, investigadora del Yale Information Society Project se pregunta en qué medida se tienen en cuenta los intereses de los países en desarrollo a la hora de definir y adoptar estándares para Internet. Existe preocupación por el creciente uso de estándares y aplicaciones sobre Internet que no se corresponden con el protocolo más conocido, el TCP/IP. Este es un factor central para los países en desarrollo que, como tales, tienen barreras de acceso (Ilegan más tarde a la innovación y al uso de nuevas tecnologías) y barreras de uso. Los nuevos estándares en Internet tienen fuertes implicancias para todos los países, pero sobre todo para los más pobres en la medida que es un problema asociado con la escalada de estándares cerrados sobre Internet y protegidos por leyes de propiedad intelectual. Esto ha llevado a que algunos países, como China, comiencen a desarrollar estándares nacional es ya que no pueden -ni quierenenfrentar los costos de estas aplicaciones. De seguir, esta política acarrea para el futuro una Internet fragmentada, ya que implica erigir barreras de acceso, incluyendo a aquellos que pueden pagar $y / 0$ que pertenecen a una comunidad o nación específica, principio contrario a la filosofía de Internet tal como la imaginaron sus creadores.

Una experiencia tan particular y con tantas perspectivas, sobre una red que pasó de ser un medio a un mundo en sí mismo, con sus propias reglas de sentido, convivencia, intercambio y sobre el cual no dejan de crecer aplicaciones hace difícil sintetizar 0 trazar un sentido o camino único sobre Internet, su presente y su futuro. Lo que queda de manifiesto es la voluntad de miles de personas y organismos de preservar un espacio nuevo que está definitivamente cambiando nuestra forma de comprender el mundo y en este sentido de mantener, valorar y legitimar aún más una forma de organización con un formato abierto y multisectorial reconocido por la ONU. A no perder de vista al IGF en estos próximos tres años de vida que aún mantendrá bajo esta forma actual.:- asociaciones de la sociedad civil y académicos. Además de las sesiones plenarias, se realizaron 84 actividades (talleres, foros de mejores prácticas y reuniones). 4::

En cuanto al acceso a Internet los representantes de países en vías de desarrollo señalaron como prioritaria la conexión del "siguiente billón" de habitantes. Hoy hay mil millones conectados. Los gobiernos reclamaron a las telcos mayores inversiones para consolidar la infraestructura básica en regiones consideradas poco lucrativas, y asumieron que deben promocionar el acceso, 10 que incluye repensar los actuales modelos de negocios y generar alianzas público-privado. 5::

El tema de la diversidad refiere a que si bien Internet es un

vehículo para la expresión de contenido y de las minorías, hay muchos individuos y culturas que no están representados. A nivel individual el conflicto radica sobre todo en las personas con discapacidades, y a nivel grupal en la excesiva predominancia del inglés. Hubo un firme consenso en Río en torno a la importancia de mantener vivas las lenguas, los dialectos locales, y el multiculturalismo en Internet. $6 .:$

En la sesión sobre apertura la discusión se centró en la relación de los protocolos de Internet y la Propiedad Intelectual. Estos dos conceptos están cada vez más unidos, lo que habla de una creciente

privatización de las aplicaciones y los contenidos que se producen sobre Internet. En este espacio cobró especial relevancia la iniciativa de los Creative and Scientific Commons, como proyectos esenciales para mantener el acceso a los conocimientos científicos y culturales. 7::

El debate acerca de la seguridad involucra la estabilidad de la estructura, la integridad de los datos, la confiabilidad de los contenidos, la lucha contra el ciber-crimen, y la privacidad de las personas. Se propuso observar a los proveedores de servicio de Internet, y brindarles marcos legales apropiados.

Foto IGF Brazil 2007 